MARIANE ROMAGNOLLO MENEZES DA SILVA

A DECISÃO JUDICIAL NO PROCESSO SEMIÓTICO

\author{
Tese de Doutorado
}

Orientadora: Professora Associada Elza Antonia Pereira Cunha Boiteux Coorientador: Professor Doutor Willis Santiago Guerra Filho

UNIVERSIDADE DE SÃO PAULO

FACULDADE DE DIREITO

São Paulo-SP

2019 
MARIANE ROMAGNOLLO MENEZES DA SILVA

\section{A DECISÃO JUDICIAL NO PROCESSO SEMIÓTICO}

Tese apresentada à Banca Examinadora do Programa de Pós-Graduação em Direito da Faculdade de Direito da Universidade de São Paulo, na área de concentração de Filosofia e Teoria Geral do Direito, como exigência parcial à obtenção do título de Doutora em Direito, sob orientação da Professora Associada Elza Antonia Pereira Cunha Boiteux e coorientação do Professor Doutor Willis Santiago Guerra Filho.

UNIVERSIDADE DE SÃO PAULO

FACULDADE DE DIREITO

São Paulo-SP

2019 
Silva, Mariane Romagnollo Menezes da

A decisão judicial no processo semiótico / Mariane Romagnollo Menezes da Silva. -- São Paulo: USP / Faculdade de Direito, 2019.

135f. + anexo.

Orientadora: Profa. Associada Elza Antonia Pereira Cunha Boiteux; Coorientador: Prof. Dr. Willis Santiago Guerra Filho.

Tese (Doutorado), Universidade de São Paulo, USP, Programa de PósGraduação em Direito - área de concentração, Filosofia e Teoria Geral do Direito, 2019.

1. Direito. 2. Linguagem. 3. Semiótica. 4. Decisão Judicial. 5. Valores. I. Boiteux, Elza Antonia Pereira Cunha. II. Título. 


\section{FOLHA DE APROVAÇÃO}

Nome: Mariane Romagnollo Menezes da Silva

Título: A decisão judicial no processo semiótico

Natureza: Tese de Doutorado

Instituição: Faculdade de Direito da Universidade de São Paulo

Orientadora: Professora Associada Elza Antonia Pereira Cunha Boiteux

Coorientador: Professor Dr. Willis Santiago Guerra Filho (Pontifícia Universidade Católica de São Paulo - PUC/SP)

Área de Concentração: Filosofia e Teoria Geral do Direito

Data da Banca:

Banca Examinadora

Profa. Associada Elza Antonia Pereira Cunha Boiteux (Orientadora) 
Aos meus pais, Mário e Magda, à minha irmã, Giulia e ao meu namorado, Vinícius. 
SILVA, Mariane Romagnollo Menezes da. A decisão judicial no processo semiótico. 2019. 135f. Tese (Doutorado). Faculdade de Direito da Universidade de São Paulo, São Paulo, 2019.

\section{RESUMO}

A partir de uma investigação zetética jurídica de abordagem epistemológica, pautada no estudo do Direito como linguagem, na teoria semiótica e no embate entre a Hermenêutica e a Argumentação jurídicas, buscamos demonstrar o processo de tomada de decisão judicial e a própria decisão judicial como um processo semiótico. Tal análise configura uma tentativa de compreender melhor o Direito materializado pelas decisões, uma vez que o enquadramento da decisão judicial como um processo semiótico nos possibilita visualizar melhor como os valores e demais influências externas influenciam cognitivamente o magistrado no processo de tomada de decisão.

Palavras-chave: Direito. Linguagem. Semiótica. Decisão Judicial. Processo Semiótico. Valores. Influências Cognitivas do Magistrado. Tomada de Decisão. 
SILVA, Mariane Romagnollo Menezes da. The judicial decision in the semiotic process. 2019. 135p. PhD Thesis, Faculty of Law, University of São Paulo, São Paulo, 2019.

\begin{abstract}
From the juridical research with an epistemological approach, based on the study of Law as a language, on the semiotic theory and on the clash between legal hermeneutics and legal argumentation, we seek to demonstrate the judicial decision-making process and the judicial decision itself as a semiotic process. This analysis constitutes an attempt to better understand the law materialized in the decisions, since the framing of the judicial decision as a semiotic process enables us to better visualize how values and other external influences influence the magistrate cognitively in the decision-making process.
\end{abstract}

Keywords: Law. Language. Semiotics. Judicial decision. Semiotic Process. Values. Cognitive Influences of the Magistrate. Decision Making. 
SILVA, Mariane Romagnollo Menezes da. La décision judiciaire dans le processus sémiotique. 2019. 135p. Thèse (Doctorat). Faculté de Droit, Université de São Paulo, 2019.

\section{RÉSUMÉ}

Sur la base d'une recherche juridique, basée sur l'étude du droit en tant que langage, sur la théorie sémiotique et sur le conflit entre l'herméneutique juridique et l'argumentation, nous cherchons à démontrer le processus décisionnel judiciaire et la décision judiciaire ellemême en tant que processus sémiotique. Cette analyse constitue une tentative de mieux comprendre le droit matérialisé par les décisions, puisque la formulation de la décision judiciaire en tant que processus sémiotique nous permet de mieux visualiser comment des valeurs et d'autres influences externes influencent cognitivement le magistrat dans le processus décisionnel.

Mots-Clé: Droit. Langue. Sémiotique. Décision judiciaire. Processus sémiotique. Valeurs. Influences cognitives du magistrat. Prise de décision. 


\section{SUMÁRIO}

INTRODUÇ̃̃̃O

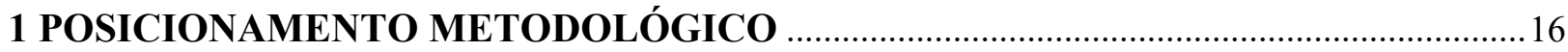

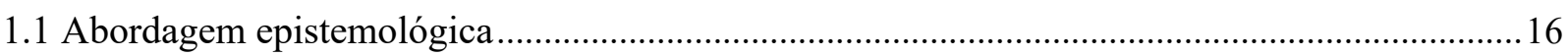

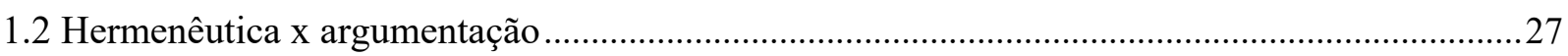

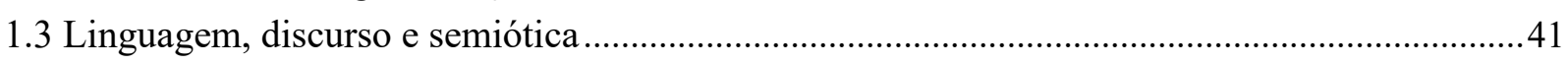

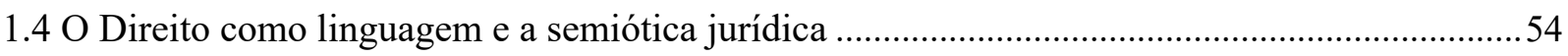

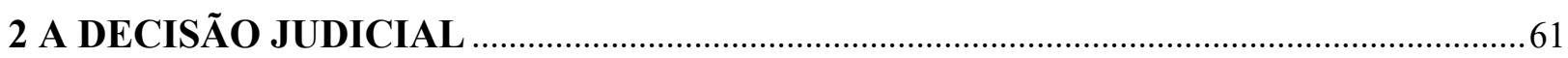

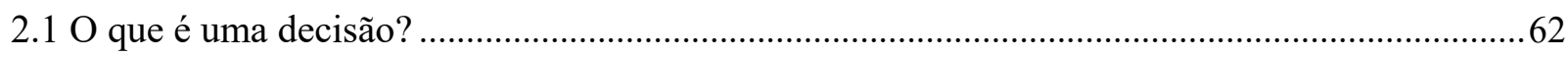

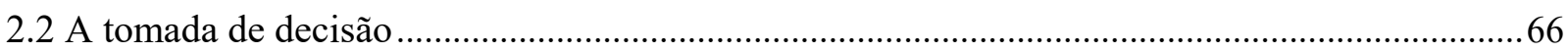

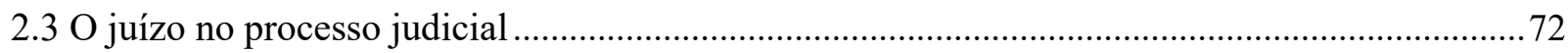

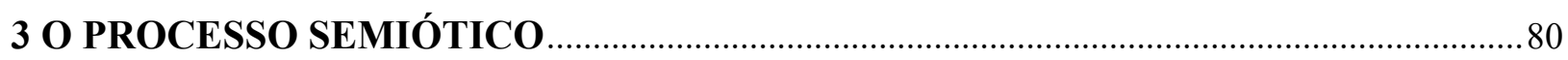

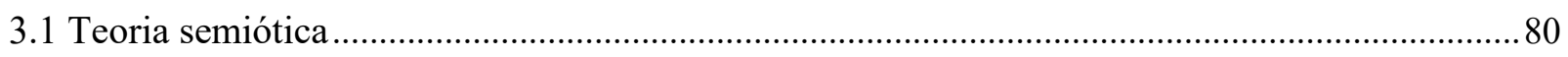

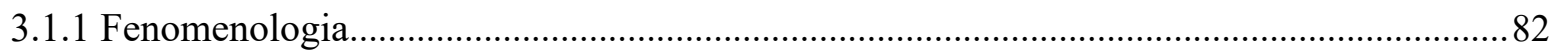

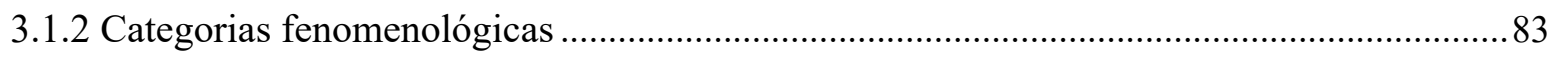

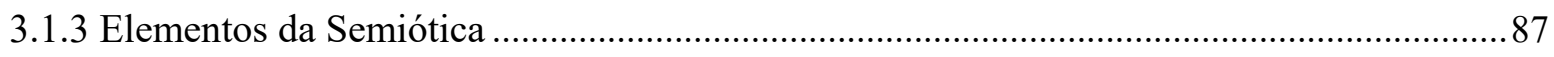

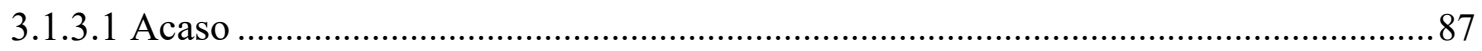

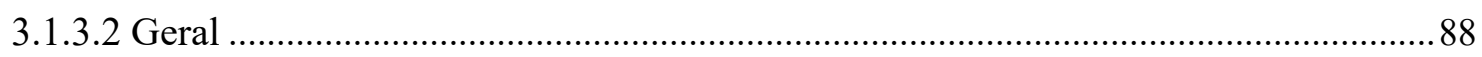

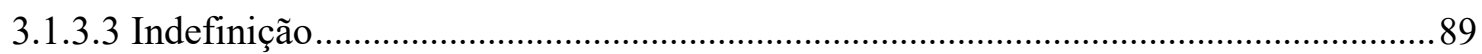

3.1.4 Relação triádica: semiose, contexto e repertório ..............................................................90

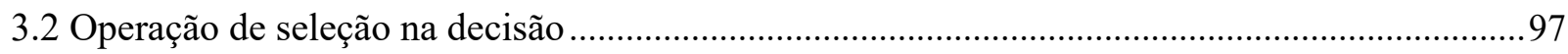

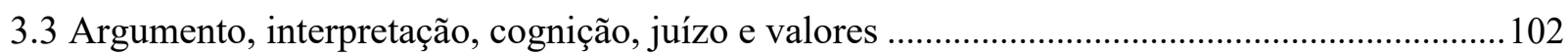

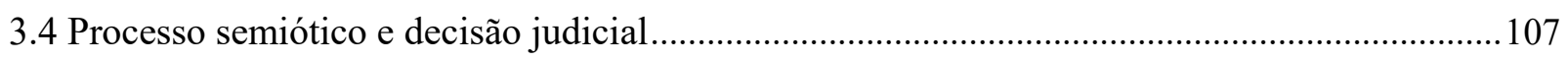

\section{ANÁLISE DE DECISÃO JUDICIAL DO ORDENAMENTO JURÍDICO}

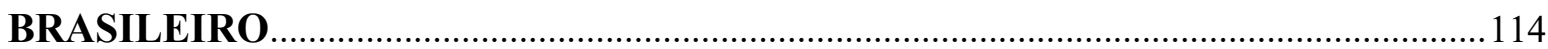

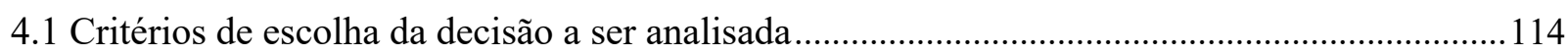

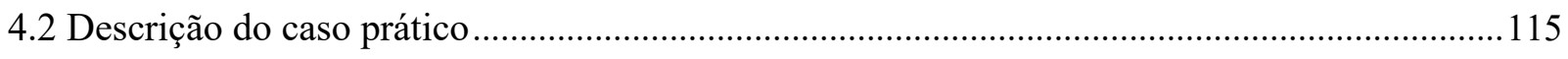

4.3 Análise da decisão judicial escolhida e aplicação da teoria ao caso concreto .............................116

CONCLUSÃO

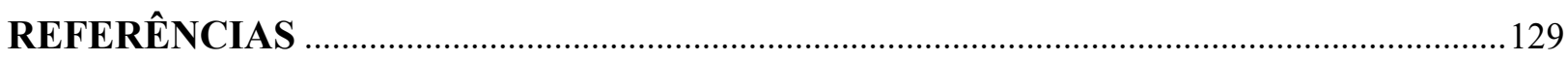

ANEXO 


\section{INTRODUÇÃO}

É um trabalho árduo definir o conceito de Direito, não só como uma ciência, mas também como uma palavra que possui significado. Não só a palavra direito, mas também a ciência do direito, fazem parte do cotidiano de todos; seja de maneira técnica, seja de forma vulgar, este é um vocábulo usado nos mais diversos sentidos: um ideal de justiça; crenças de uma determinada sociedade; filosofias de obediência; sustentação moral; entre outros.

Ademais, a palavra direito não é apenas um signo com múltiplos significados, mas também pode representar um instrumento "que frustra as aspirações dos menos privilegiados e permite o uso de técnicas de controle e dominação que, por sua complexidade, é acessível apenas a uns poucos especialistas" ${ }^{1}$.

Uma tentativa de definição do Direito, como fenômeno jurídico, considera a origem da palavra para tentar atribuir o seu significado, o que também se torna difícil; uma vez que encontramos no latim clássico, tanto a palavra jus quanto a palavra derectum. Em decorrência disso, nos deparamos com o problema da polissemia da palavra direito e de seus inúmeros conceitos.

Reinhart Koselleck ${ }^{2}$ nos ensina que nem toda palavra existente tem a possibilidade de se transformar num conceito, ou ter uma história; para ele "cada palavra remete a um sentido, que por sua vez indica um conteúdo". Ademais, um conceito "relaciona-se sempre àquilo que se quer compreender, sendo portanto a relação entre o conceito e o conteúdo a ser compreendido, ou tomado inteligível, uma relação necessariamente tensa."”3

O conceito de uma palavra existe diante de um certo contexto e é isso que o torna compreensível; é o que podemos notar ao analisar alguns símbolos relacionados ao Direito, que antecedem a própria palavra: o mais importante deles, na cultura ocidental, é a balança. Por exemplo, na Grécia Antiga, a balança aparece nas mãos da deusa da justiça Diké -, representando a igualdade por meio do equilíbrio entre os pratos, o que justifica o fato de Direito (justo) significar igualdade para os gregos.

\footnotetext{
${ }^{1}$ FERRAZ JR, Tércio Sampaio. Introdução ao estudo do direito: técnica, decisão e dominação. 6. ed. São Paulo: Atlas, 2008. p. 10.

${ }^{2}$ KOSELLECK, Reinhart. Uma história dos conceitos: problemas teóricos e práticos. Revista Estudos Históricos, Rio de Janeiro, v. 5, n. 10, p. 135, jul. 1992. ISSN 2178-1494. Disponível em: $<$ http://bibliotecadigital.fgv.br/ojs/index.php/reh/article/view/1945>. Acesso em: 03 jul. 2018.

${ }^{3}$ Id. Ibid., p. 136.
} 
Enquanto que na sociedade romana a balança é o instrumento de distribuição de justiça carregado pela deusa Iustitia, a qual declarava o Direito (jus) quando o fiel da balança estivesse totalmente na vertical; ou seja, perfeitamente reto (rectum).

Dessa maneira, pela simbologia das suas deusas da justiça e seus respectivos contextos, as sociedades ocidentais acabavam por indicar o que representava o conceito de Direito para elas; seja como prudência ou como um saber agir. O fato é que, com a passar dos tempos, a expressão jus foi sendo substituída pela expressão derectum, a qual foi adotada também pelos juristas.

Em português, no entanto, a palavra direito é concebida tanto no sentido de jus, como uma virtude moral (justiça), quanto no sentido de derectum, como um ato de justiça, de retidão. Sendo assim, como um fenômeno de grande amplitude, não se pode desprezar as diferenças de sentido e conceituações do Direito, pois só assim será possível compreendê-lo.

Nesse sentido, Tércio Sampaio Ferraz Júnior ${ }^{4}$ postula a importância da concepção da língua para a efetiva compreensão do que é o Direito, no geral, e das suas inúmeras definições (direito como ciência, direito como sinônimo de conjunto de normas, direito como sinônimo de ordenamento jurídico, direito subjetivo ou objetivo, direito como ciência, etc.).

Segundo o supracitado autor:

\begin{abstract}
A língua é vista como um sistema de signos, cuja relação com a realidade é estabelecida arbitrariamente pelos homens. Dado esse arbítrio, o que deve ser levado em conta é o uso (social ou técnico) dos conceitos, que podem variar de comunidade para comunidade. Desse modo, a caracterização de um conceito desloca-se da pretensão de buscar a natureza ou essência de alguma coisa (que é a mesa?) para a investigação sobre os critérios vigentes no uso comum para usar uma palavra (como se emprega 'mesa'?). Se nos atemos ao uso, toda e qualquer definição é nominal (e não real), isto é, definir um conceito não é a mesma coisa que descrever uma realidade, pois a definição da realidade depende de como definimos o conceito e não o contrário. ${ }^{5}$
\end{abstract}

Diante dessa preocupação, ao tentar definir um conceito, deve-se ater também aos diferentes ângulos de uma análise linguística; que pode ser sintática (relação entre o vocábulo e os demais vocábulos), semântica (relação entre o vocábulo e o objeto que ele representa), ou pragmática (relação entre o vocábulo e o indivíduo que o interpreta).

${ }^{4}$ FERRAZ JR, Tércio Sampaio. Introdução ao estudo do direito: técnica, decisão e dominação, cit., p. 12. ${ }^{5}$ Id., loc. cit. 
No entanto, o termo direito pode ser utilizado das mais variadas maneiras no plano sintático (conectado com verbos, com substantivos, com adjetivos e advérbios); no plano semântico, pode ser usado com sentido denotativo ou conotativo; e, por fim, no plano pragmático, direito apresenta uma forte carga emotiva, demonstrando mais uma vez a complexidade de definição dessa palavra.

Para Marcelo Jasmin e João Feres Júnior ${ }^{6}$ um conceito ligado a uma palavra é mais que esta palavra; uma palavra pode ser não ambígua, mas um conceito não. Dessa forma, a relação entre o conceito e o quadro linguístico mais abrangente que os contém. Os significados de um conceito e suas mudanças seriam inapreensíveis se fora de um contexto abrangente. Dessa forma, os conceitos não mudam no tempo, estão sempre relacionados a suas experiências, são os leitores posteriores que dão a esses conceitos significados distintos, mais ou menos associados aos anteriores.

Assim, resta-nos a tentativa de redefinir o termo direito, mantendo o seu valor emotivo, salientando que existem outras opções e deixando clara a nossa opção valorativa e, consequentemente, ideológica. Redefinir um conceito, no entanto, "envolve o seu conhecimento, mas este conhecimento tem sempre repercussão na vida jurídica"7.

Sob esta ótica, o objeto de estudo do jurista só se realiza por meio de uma prática interpretativa; uma vez que a teoria jurídica evolui e se transforma à medida em que é estudada e interpretada. Dessa forma, a concepção da língua, para o jurista, não possui apenas o aspecto informativo, mas também o diretivo - "a ciência jurídica não apenas informa, mas também conforma o fenômeno que estuda, faz parte dele"»; assim, um conceito jurídico, assim como o próprio conceito de direito, não é apenas o que é socialmente, mas também como é interpretado.

Posto isso, concluímos que o Direito, como objeto de estudo, seja como palavra ou como ciência, pode e deve ser estudado de diferentes ângulos: pode ser um enfoque que busca saber o que é uma coisa - o zetético (problema especulativo), ou um enfoque que busca possibilitar uma decisão e dirigir uma ação - o dogmático (problemas de ação).

É justamente no enfoque zetético que predomina a função informativa da linguagem; dessa forma, assim como em nossa linguagem comum fazemos constatações nas nossas comunicações, no plano da zetética, também buscamos transmitir informações

\footnotetext{
${ }^{6}$ JASMIN, Marcelo Gantus; FERES JÚNIOR, João (Orgs.). História dos conceitos: debates e perspectivas. Rio de Janeiro: PUC-RJ; São Paulo: Loyola, 2006. p. 125-126.

${ }^{7}$ FERRAZ JR, Tércio Sampaio. Introdução ao estudo do direito: técnica, decisão e dominação, cit., p. 16. ${ }^{8}$ Id. Ibid., p. 17.
} 
por meio de um conjunto de enunciados. Partimos de evidências, para verificar hipóteses ou leis.

Dessa forma,

O campo das investigações zetéticas do fenômeno jurídico é bastante amplo. Zetéticas são, por exemplo, as investigações que têm como objeto o direito no âmbito da Sociologia, da Antropologia, da Psicologia, da História, da Filosofia, da Ciência Política etc. Nenhuma dessas disciplinas é especificamente jurídica. Todas elas são disciplinas gerais, que admitem, no âmbito de suas preocupações, um espaço para o fenômeno jurídico. ${ }^{9}$

Da mesma maneira, encontramos no campo das investigações da zetética jurídica, o estudo da linguagem relacionado ao direito; relação esta abordada tanto no questionamento sobre o significado do direito como palavra, quanto na investigação do conceito de direito como uma ciência, como um fenômeno social, deixando clara a interdependências dessas duas ciências que representam a linha de pesquisa desta pesquisa.

O discurso jurídico, de forma geral, se caracteriza como uma linguagem técnica; constrói-se com base em experiências de vida; é dotado de ideologia; ocorre intraculturalmente; exerce poder; possui caráter performativo; e por fỉm, sua apresentação se dá por meio de pressupostos lógico-deônticos ${ }^{10}$.

Cabe-nos afirmar ainda, que:

Os textos jurídicos são molas propulsoras da ação. A linguagem jurídica funciona como ponto de partida para as ações sociais e o movimento das relações humanas. Negocia-se, patenteia-se, registra-se, autoriza-se e pactua-se, tudo com base em textos e signos jurídicos. São eles que informam ou regulamentam ações humanas juridicamente relevantes. No entanto, signos e textos jurídicos (normativos) não movimentam ação fortuitamente, e não contam com o livre-arbítrio, com a capacidade de argumentação, de sedução do locutor discursivo, ou com a paixão ética ou o interesse do receptor discursivo. [...] Signos e textos jurídicos são molas propulsoras da ação porque movimentam condutas, regendo-as de forma quase que onipotente (omnipotens) e onipresente (ominpresens). E mais, acompanham-se da força bruta, no dizer de Peirce. Sua existência e seu reconhecimento em meio às práticas sociais e intersubjetivas condicionam o comportamento humano. ${ }^{11}$

${ }^{9}$ FERRAZ JR, Tércio Sampaio. Introdução ao estudo do direito: técnica, decisão e dominação, cit., p. 21. ${ }^{10}$ BITTAR, Eduardo Carlos Bianca; ALMEIDA, Guilherme Assis de. Curso de filosofia do direito. 6. ed. São Paulo: Atlas, 2008. p. 557.

${ }^{11}$ Id. Ibid., p. 564. 
É exatamente sob esse enfoque, conectando o Direito e a linguagem ao chamado discurso jurídico, que se pretende estudar o tema da decisão judicial no processo semiótico.

Trata-se aqui da decisão judicial como uma categoria do Direito, não pretendemos explorar a dogmática processual envolvendo o conceito de decisão judicial e os tipos de decisão judicial no direito processual brasileiro. Apresentamos, então, a decisão judicial como derivada do "termo decisão [...] ligado aos processos deliberativos" constituídos por “estados psicológicos de suspensão do juízo diante de opções possíveis", aparecendo então a decisão como "um ato final, em que uma possibilidade é escolhida", conforme afirma Tércio Sampaio Ferraz Júnior ${ }^{12}$.

Diante disso, de acordo com o que será estudado no segundo capítulo, o termo decisão judicial utilizado nessa tese se refere à decisão de um conflito jurídico. Considerando-se que os "conflitos jurídicos têm a ver com a possibilidade de exigência da emissão ou recepção de mensagens" ${ }^{13}$, ocorrendo uma situação comunicativa estruturada, a qual se submete a uma coordenação objetiva de um terceiro comunicador (juiz) e que esta vincula as ações dos receptores (partes), a decisão judicial é aquele capaz de impedir a continuação de um conflito jurídico, por meio de uma resposta, impondo-o um fim.

O problema maior enfrentado nesse âmbito da decisão judicial é que no contexto pluralista e aberto do sistema jurídico atual há um grande campo para o chamado terceiro comunicador - o intérprete/juiz, “que deve 'reconstruir' o Direito do caso mediante um processo de seleção de leis, costumes, normas administrativas, normas constitucionais, princípio e valores"14. Ou seja, apresenta-se, a decisão judicial, como um "problema de construção do juízo deliberativo pelo juiz"15.

Diante desse prisma, a análise da decisão judicial no processo semiótico configura a tentativa de enquadrar o próprio processo de construção da chamada decisão judicial como um processo semiótico. Ou seja, considerando semiótica como a ciência que estuda os signos e considerando o próprio Direito como uma linguagem expressada pelo discurso jurídico que se materializa na decisão judicial, o processo semiótico vem a ser o processo pelo qual o juiz toma sua decisão e constrói a decisão judicial.

\footnotetext{
${ }^{12}$ FERRAZ JR, Tércio Sampaio. Introdução ao estudo do direito: técnica, decisão e dominação, cit., p. 286.

${ }^{13}$ Id. Ibid., p. 288.

${ }^{14}$ LORENZETTI, Ricardo Luís. Teoria da decisão judicial: fundamentos de direito. 2. ed. São Paulo: Revista dos Tribunais, 2010. p. 35.

${ }^{15}$ FERRAZ JR, Tércio Sampaio. Introdução ao estudo do direito: técnica, decisão e dominação, cit., p. 290.
} 
Isso porque, nesse processo de confeccionar a decisão judicial, o intérprete - juiz, terceiro comunicador - como foi visto, enfrenta subjetividades, colocando em sua "resposta" toda a sua carga de valoração pessoal, o que é estudado pelo nível pragmático da linguagem e, portanto, pela semiótica.

Entendemos o processo semiótico como o próprio processo de desenvolvimento da decisão judicial, no qual acontecem sucessivas semioses na mente do intérprete até que ele solucione o conflito colocado à sua frente. Decorre daí o fato de abordarmos o tema da decisão judicial como sendo um processo semiótico; uma vez que como foi visto, a decisão judicial trata de um problema de valoração e construção do juízo deliberativo pelo intérprete/terceiro comunicador/juiz.

Dessa forma, devemos deixar claro que, nesta tese, a semiótica não é utilizada como um método de interpretação da decisão judicial: a própria decisão judicial será analisada como sendo um processo semiótico em si.

Há de se ressaltar que, no entanto, não se trata de uma abordagem que descarte as outras formas de interpretação da decisão judicial, como a hermenêutica; pretende-se aqui, apenas mostrar uma outra forma de análise, sob o enfoque de um paradigma diferente. Ou seja, busca-se apenas tentar compreender o direito materializado pela decisão judicial de uma forma diversa das já existentes; acreditando-se que essa inovação poderá ser capaz de compreendermos melhor o próprio Direito.

Posto isso, o termo Direito nesta tese não se reduz ao direito brasileiro, aplicado em face das normas constitucionais e processuais do ordenamento jurídico pátrio; mas sim o direito em geral; ou seja, à Teoria Geral do Direito, que engloba a Ciência do Direito, como veremos no primeiro capítulo.

Seja no ordenamento jurídico brasileiro, seja no ordenamento jurídico de qualquer outro país, existe decisão judicial e ela pode ser analisada sob o enfoque pretendido nesse trabalho, a fim de se compreender o direito como a ciência que é.

Por fim, embora tenha havido uma opção pela abordagem filosófica, não há como se preterir totalmente a dogmática, visto que, de certa forma, elas caminham juntas e são interdependentes. Em que pese a intenção empírica de demonstração da teoria diante da análise de um acórdão do direito pátrio, não se está limitando o tema tratado aqui ao direito processual brasileiro, justamente com o intuito de que a presente pesquisa possa ser, de certa forma, universal, no campo da epistemologia jurídica. 
Para tanto, as principais questões a serem analisadas nesta tese são as seguintes: Como se dá o processo de construção da decisão judicial? Como o juiz processa as informações ao decidir uma causa e dizer qual das partes tem razão? Quais atalhos $\operatorname{cognitivos}^{16}$ influenciam esse processo? Poderíamos analisar a decisão judicial de forma filosófica, como sendo um processo semiótico, a fim de desenvolver uma melhor compreensão do seu papel no Direito?

Diante dessa análise, veremos que a decisão judicial como um processo semiótico, uma vez que o seu processo de construção se dá por meio da semiose, poderá nos ajudar a compreender melhor o Direito na prática.

Em virtude disso, o intuito da presente pesquisa é realizar uma análise filosófica sobre o processo de tomada de decisão e de construção da decisão judicial, com base na teoria semiótica; de modo a demonstrar o processo de tomada de decisão e da construção da decisão judicial como um processo semiótico, como veremos no terceiro capítulo.

Diante dessa preocupação, buscamos tentar entender o funcionamento semiótico do processo de tomada de decisão no âmbito jurídico; ou seja, antes de buscar uma alternativa para melhoria do sistema, pretende-se entender os seus alicerces, para então poder transformá-lo.

Ademais, acreditamos que o estudo da Semiótica ligado ao Direito, embora crescente, ainda é incipiente no direito brasileiro; uma vez que é necessário um grande esforço racional para unir um ramo científico "recente" a outro tão tradicional e tradicionalista quanto o jurídico.

Sendo assim, a análise do processo de tomada de decisão como um processo semiótico pode vir a representar um grande avanço da virada linguística da filosofia pósmoderna; podendo gerar uma mudança de paradigmas no campo da ciência jurídica brasileira; trazendo originalidade.

Dessa maneira, pretende-se realizar uma investigação zetética jurídica de abordagem epistemológica, pautada no embate entre a Hermenêutica e a Argumentação

\footnotetext{
${ }^{16}$ Atalhos cognitivos são caminhos mais rápidos e fáceis acessados pela mente durante o processo de tomada de decisão e julgamento. Geralmente são formados por lembranças e experiências que ficaram gravadas em nossa memória e que são acionadas rapidamente diante de determinadas situações, por força do hábito ou dos costumes/crenças da pessoa, de forma até mesmo inconsciente; sem que haja um grande exame de raciocínio prévio acerca da questão sobre a qual se está decidindo. Então, de certa forma, atalhos cognitivos são repostas pré-determinadas de uma pessoa diante de um caso concreto que se lhe apresente. Assim, esse condicionamento, acaba por influenciar no processo de tomada de decisão e varia de indivíduo para indivíduo.
} 
jurídicas, buscando-se realizar uma análise do processo de tomada de decisão judicial e da própria decisão judicial como um processo semiótico.

Para abordar toda a problemática desenvolvida nesta tese em seus primeiros capítulos e demonstrar o funcionamento da decisão judicial como um processo semiótico, bem como deixar claras as influências externas do magistrado durante o processo de tomada de decisão, no quarto e último capítulo realizaremos a análise de um acórdão do Tribunal de Justiça de São Paulo sobre a competência da Vara da Família e Sucessões para decidir sobre ações referentes à posse e regularização de visitas de um animal de estimação. 


\section{CONCLUSÃO}

Como vimos no primeiro capítulo, é preciso que a filosofia do direito se socorra de outros recursos técnicos e científicos para auxiliá-la na análise do direito e no desenvolvimento de sua realidade social.

Por meio da nossa abordagem epistemológica - diante da qual a epistemologia jurídica é considerada a responsável por de gerar conhecimento e compreender o direito, a sua filosofia, a sua ciência e a sua teoria, de toda e qualquer forma - e do tratamento do direito como um fenômeno de linguagem unido a uma postura crítica do direito como transformador da sociedade é que chegamos às nossas conclusões finais.

Diante disso, afirmamos que o dilema da decisão judicial e da norma são a principal manifestação prática do direito; uma vez que o destaque assumido pela função judicial e decisória do direito faz parte da crescente preocupação com o raciocínio jurídico.

Assim, o debate epistemológico do direito atual é relacionado à experiência dos indivíduos que vivem numa sociedade e estão envoltos pela práxis social do seu ordenamento jurídico. Então, a epistemologia irá se ocupar em criticar os critérios objetivos dos juízos de valor e regras da lógica formal utilizados pelos dogmáticos no desenvolvimento da teoria geral do direito.

Como explicamos, questões e problemas jurídicos não podem ser simplesmente enquadrados numa fórmula estática sem ao menos se considerar as valorações racionais, ideológicas e emotivas envolvidas na análise do processo de tomada de decisão e na aplicação do direito.

Diante disso, analisamos que os juristas, como qualquer ser humano, são incapazes de realizar sua atividade de maneira satisfatória sem realizar escolhas e julgamentos de valor; ou seja, sem exercitar suas vontades e expressar suas preferências subjetivas e por isso, a dogmática jurídica deve ser repensada, devendo ser trabalhada em uma perspectiva criativa/criadora.

Portanto, acreditamos que apenas diante dessa abordagem é possível entender a estrutura cognitiva da decisão judicial no ordenamento jurídico - como um sistema que é mutável, mas que para garantir a sua integridade, realizar sua função social e gerar as transformações necessárias, deve cumprir sua função normativa sem extrapolar totalmente os seus limites legais; afinal, o direito é construído pela teoria que dele trata. 
No segundo capítulo discorremos que a atividade dos juristas é realizada por meio da interpretação e pressupõe a compreensão não só do caso, mas do sentido e da atribuição de um valor à norma que será aplicada. Por esse viés, concluímos que o objetivo do jurista não é apenas conhecer e/ou interpretar o texto normativo, mas sim confrontá-lo ao problema, determinando sua força e alcance para solucionar a questão.

O Direito trata-se de um fenômeno, uma experiência, não apensa social, mas de linguagem; e, assim sendo, o jurista não pode deixar de considerar essa realidade, essencialmente histórica, como a de qualquer outra estrutura social, ao analisar as normas. O Direito trata-se também de um discurso jurídico, o qual trata da justificação de um caso especial de proposições normativas, as decisões judiciais.

A aplicação do direito, nesse contexto, deverá se voltar tanto à lei, quanto à realidade, uma vez que os fatores sociológicos, culturais, ideológicos e até psicológicos influenciam na interpretação dos signos; pois o discurso jurídico é ideológico na medida em que pressupõe decisões.

Diante da decisão - como um ato de comunicação - temos um discurso racional de uma pessoa para outra pessoa, com intuito de que o que está sendo comunicado seja compreendido e atendido. É nesse horizonte que se dá a importância da semiótica para a trasnformação total da filosofia no giro pragmático-semiótico; pois a relação triádica de Peirce é essencial para a compreensão de que a interpretação de algo como algo é o resultado da interpretação de alguém, por meio dos signos.

A relação triádica peirceana possibilita não apenas a interpretação do mundo e da ciência, mas também o pensamento e a pretensão de verdade de qualquer compreensão. Os signos realizam a mediação entre o ser e a coisa, o homem e o objeto, tornando possível que o homem descreva e interprete algo que é de seu conhecimento de forma válida.

Observamos então que a Semiótica Jurídica analisa o Direito sob o ponto de vista da juridicidade, da sua produção textual; e seu papel, mais do que analisar os signos, é analisar a significação do sistema jurídico.

E assim, concluímos que o desenvolvimento de uma nova teoria do direito é resultado da aproximação da interpretação de textos constitucionais no exercício da jurisdição constitucional quando se trata dos hard cases ou casos difíceis, os quais necessitam da utilização de princípios por não serem satisfatoriamente resolvidos apenas com a aplicação das normas jurídicas. 
Vimos no segundo capítulo que o resultado da interpretação e uso de normas legais e princípios nos ensina que o ato de sentenciar não se trata de um ato puramente racional e controlado/controlável, pois a decisão jurídica, antes de mais nada, se apresenta como um problema de juízo deliberativo do juiz.

Dessa forma, concluímos que o maior problema envolvendo o tema da decisão judicial é a subjetividade existente no processo de tomada de decisão, uma vez que este se trata de um ato humano de comunicação, sendo influenciado das mais diversas maneiras pelo seu prolator; o que coloca em jogo a racionalidade e a consequente segurança jurídica esperada diante de um discurso jurídico baseado num sistema legal.

Quando se decide, prefere-se uma situação ou solução em detrimento de outra; e essa ação de preferir, de escolher uma alternativa, é inegavelmente realizada diante de um juízo de valor. Apesar de o ato de julgar ser compreendido como uma tarefa de subsunção, estão presentes a interpretação e a compreensão do conflito existente e dessa forma, a convicção do juiz se apresenta mais como uma intuição, um sentimento, do que como um raciocínio.

Vimos que o momento de formação da convicção pelo juiz é um momento subjetivo, havendo quem acredite que a razão ou fundamento para essa convicção pessoal do julgador obedece apenas ao instinto, o sentimento e o pensamento internos; sem se submeter a uma racionalidade controlada ou controlável. Assim, racionalidade está presente não no momento em que o juiz pensou, mas sim no momento em que ele justificou suas razões para decidir; ou seja, durante a motivação.

A mente do juiz antecipa a decisão que considera justa e depois procura a norma que pode servir de fundamento para essa solução; o que corrobora a existência de aspectos extra lógicos, relacionados à subjetividade do juiz no processo decisório. Então, apesar das regras do ordenamento jurídico serem a base de toda decisão judicial, elas não são exclusivamente o embasamento de tais decisões; a personalidade daquele que decide influi, e muito, na tomada de decisão.

A consequência disso é que na aplicação do Direito não é possível existir segurança, certeza e uniformidade; uma vez que nas sociedades complexas as decisões jurídicas possuem um caráter plástico e mutável, cujo papel é se adaptar às mudanças da 
sociedade. É justamente essa incerteza, de acordo com Jerome Frank ${ }^{348}$, que gera o progresso do Direito, que o faz se modificar e evoluir.

Concluímos assim, que o direito se aperfeiçoa não apenas por meio das regras abstratas, mas também pela ação humana; a personalidade do juiz é um aspecto importante da sentença, restando claro que a decisão não se limita a um juízo lógico, a humanidade do juiz está presente na sentença.

Diante disso, no terceiro capítulo vimos que a semiótica é uma teoria e um método capaz de explicar o processo pelo qual os valores e juízos de valor se desenvolvem e acumulam significado; tornando-se essencial para compreendermos o processo de tomada de decisão, na medida em que a observação colateral, como objeto direto, é a responsável por influenciar na formação do interpretante do signo durante o processo semiótico.

Por meio da semiose - uma associação triádica, na qual o signo representa um objeto na mente e gera uma ideia nessa mente, que é chamada de interpretante - notamos que as operações de seleção e de combinação do sujeito que está interpretando algo ou expressando uma ideia na forma de linguagem - no caso, o juiz de direito no processo de tomada da decisão judicial - são totalmente influenciadas pelo contexto.

Dessa forma, o processo cognitivo presente em toda semiose gera um hábito ou uma lei na mente do intérprete e assim, toda vez que o intérprete se depara com situações parecidas é o resultado daquelas semioses passadas que lhe virá a memória e influenciará as semioses futuras; exatamente como ocorre na mente do magistrado ao se decidir sobre um caso que lhe remeta a experiências pessoais anteriores.

Em virtude disso é que os valores acabam por agir como grandes influenciadores das decisões judicias e por essa razão, na tentativa de fazer com que o Direito expresse o valor da justiça, toda e qualquer decisão irá positivar um valor e, consequentemente, revelar um juízo de preferência por meio do argumento utilizado na fundamentação da decisão.

Afirmamos então, que tanto os valores pessoais, como o contexto, incidem na interpretação de uma lei e na tomada de decisão, modificando o interpretante. É assim que ao interpretar uma norma, proferir uma sentença e argumentar em favor de sua decisão, o juiz muda o resultado da semiose e transforma o próprio Direito.

${ }^{348}$ FRANK, Jerome. op. cit. 
Ademais, acreditamos que a ponderação de princípios realizada por aquele que decide será diretamente realizada por meio de critérios de valoração do próprio decididor; ou, em outras palavras, o sopesamento de princípios conflitantes é realizado por meio dos valores do magistrado que decide.

A decisão judicial, portanto, irá positivar um valor e revelar o juízo de preferência daquele que a proferiu, o qual se demonstra por meio do argumento utilizado; se revelando ela mesma, a decisão judicial, como um processo semiótico dentro do sistema do Direito.

É assim que os processos judiciais são capazes de perseguir os valores do Direito e da sociedade, bem como a estabilidade das relações intersubjetivas; servindo à finalidade do processo e isso ocorre quando se chega à decisão judicial, seja ela irrecorrível ou não.

Apenas com o processo judicial completo é que poderá se obter a decisão judicial, ou seja, o interpretante esperado desde o início do processo. Dessa forma, enquadramos a decisão judicial como uma grande semiose; ou melhor, como a semiose final originada pela cadeia de semioses que formaram o processo.

Assim, no terceiro capítulo concluímos que a decisão judicial é o interpretante final de uma cadeia metalinguística de desenvolvimento de um processo; ou seja, o processo de tomada de decisão é um processo semiótico.

Por fim, no quarto capítulo mostramos que a subjetividade do juiz se revela por meio da sua argumentação dada diante da sua escolha para solucionar um conflito, da sua interpretação da lei e do seu sopesamento de valores. Esse resultado foi obtido demonstrando-se a decisão judicial como um processo semiótico, o qual sofre influências do objeto direto na formação do interpretante, o que ocasiona transformações no eixo paradgmático da operação de seleção e combinação realizada pelo magistrada na tomada de decisão.

Diante da análise do processo decisório como um processo semiótico pudemos distinguir os valores pessoais que influenciaram nas decisões prolatadas pela primeira e pela segunda instâncias e como tais valores são capazes de modificar o próprio direito material.

Isso posto, podemos afirmar que a análise realizada nesta tese se destaca como uma forma eficaz de compreensão do direito, principalmente no que diz respeito à problemática da subjetividade na decisão judicial; revelando os atalhos cognitivos do magistrado durante o processo de tomada de decisão. 
O processo de tomada de decisão visto como uma semiose nos fornece a possibilidade de observar de forma mais clara os elementos não jurídicos que fazem parte de toda decisão; sendo não só possível elencá-los, mas também, de certa forma, traçar uma espécie de perfil psicológico do magistrado que decide. Isso pode ajudar a "prever", de forma mais exata, o resultado de futuras decisões envolvendo o mesmo tema.

Ademais, diante de tal análise, é possível debater com mais exatidão sobre a existência ou não do famigerado ativismo judicial em cada decisão; uma vez que os limites entre a interpretação e a criação do direito se tornam mais evidentes em face da análise do contexto que influencia e do argumento que fundamenta o processo de tomada de decisão. 


\section{REFERÊNCIAS}

ABBAGNAMO, Nicola. Dicionário de filosofia. Tradução de Alfredo Bosi e Ivone Castilho Benedetti. São Paulo: Martins Fontes, 1999.

ALEXY, Robert. Teoria da argumentação jurídica: a teoria do discurso racional como teoria da fundamentação jurídica. Tradução: Zilda Hutchinson Schild Silva; revisão técnica da tradução e apresentação à edição brasileira: Cláudia Toledo 3. ed. Rio de Janeiro: Forense, 2011.

Teoría de los derechos fundamentales. Ernesto Garzón Valdés, Madrid: Centro de Estudios Políticos y Constitucionales, 2002.

- Teoria discursiva do direito. Organização, tradução e estudo introdutório Alexandre Travessoni Gomes Trivisonno. Rio de Janeiro: Forense Universitária, 2014.

APEL, Karl-Otto. Transformação da filosofia I: filosofia analítica, semiótica, hermenêutica. Tradução de Paulo Astor Soethe. São Paulo: Loyola, 2000.

ARAÚJO, Clarice von Oertzen. Semiótica do direito. São Paulo: Quartier Latin, 2005.

ARAÚJO, Francisco Fernandes de. A parcialidade dos juízes. Campinas: Edicamp, 2002.

BARROS, Diana Luz Pessoa de. Teoria semiótica do texto. 4. ed. São Paulo: Ática, 2008.

BENVENISTE, Emile. Problemas de lingüística geral I. Trad. Maria da Glória Novak e Maria Luisa Neri. 5. ed. São Paulo: Pontes, 2005.

. Problemas de lingüística geral II. Trad. Eduardo Guimarães. 2. ed. São Paulo: Pontes, 2006.

BERMAN, Marshall. Tudo que é sólido desmancha no ar: a aventura da modernidade. Tradução de Carlos Felipe Moisés e Ana Maria L. Ioriatti. 2. ed. São Paulo: Companhia das Letras, 2006.

BITTAR, Eduardo Carlos Bianca. O direito na pós-modernidade. 2. ed. Rio de Janeiro: Forense, 2009. Atlas, 2008.

; ALMEIDA, Guilherme Assis de. Curso de filosofia do direito. 6. ed. São Paulo:

CAMPILONGO, Celso Fernandes. Interpretação do direito e movimentos sociais. Rio de Janeiro: Elsevier, 2012. 
CAMPILONGO, Celso Fernandes. Política, sistema jurídico e decisão judicial. 2. ed. São Paulo: Saraiva, 2011.

CAPELLA, Juan-Ramón. El derecho como lenguaje: un análisis lógico. Barcelona: Ariel, 1968.

CARNIO, Henrique Garbellini. Princípios da proporcionalidade e da razoabilidade: apontamentos a partir da teoria alemã da proporcionalidade. Revista Jurídica UNIARAXÁ, Araxá, v. 15, n. 14, p. 101-112, 2011.

CARRIÓ, Genaro R. Notas sobre derecho y lenguaje. 4. ed. Buenos Aires: AbeledaoPerrot, 1994.

COHEN, Felix. El metodo funcional en el derecho. Trad. Genaro R. Carrió. Buenos Aires: Abeledo Perrot, 1962.

COSTA, Regenaldo da. Ética e Discurso em Apel. Belo Horizonte: Del Rey, 2002.

COUTURE, Eduardo Juan. Introdução ao estudo do processo civil. Tradução de Mozart Victor Russomano. 3. ed. 4. tir. Rio de Janeiro: Forense, 2001.

FERRAZ JR, Tércio Sampaio. Direito, retórica e comunicação: subsídios para uma pragmática do discurso jurídico. 3. ed. São Paulo: Atlas, 2015.

Estudos de filosofia do direito: reflexões sobre o poder, a liberdade, a justiça e o direito. 3. ed. São Paulo: Atlas, 2009.

Introdução ao estudo do direito: técnica, decisão e dominação. 6. ed. São Paulo: Atlas, 2008.

FLUSSER, Vilém. Língua e realidade. São Paulo: Annablume, 2004.

FOUCAULT, Michel. A arqueologia do saber. Tradução de Luiz Felipe Baeta Neves. 7. ed. Rio de Janeiro: Forense Universitária, 2008.

FRANK, Jerome. Law and the modern mind. New York: Anchor, 1948.

GUERRA FILHO, Willis Santiago. Estudos jurídicos: teoria do direito civil. Fortaleza: Imprensa Oficial do Ceará, 1985.

. Processo constitucional e direitos fundamentais. 5 ed. São Paulo: RCS, 2007.

. Teoria da ciência jurídica. 2. ed. São Paulo: Saraiva, 2009.

2015.

; CANTARINI, Paola. Teoria poética do direito. Rio de Janeiro: Lumen Juris, 
GUERRA FILHO, Willis Santiago; CARNIO, Henrique Garbellini. Teoria da ciência jurídica. 2. ed. São Paulo: Saraiva, 2009.

HARTSHORNE, Charles; WEISS, Paul; BURKS, Arthur (Eds.). The collected papers of Charles Sanders Peirce. Cambridge: Harvard University Press, 1931-1935 e 1958 [8 volumes; obra aqui referida como $\mathrm{CP}$, acompanhado de volume e parágrafo].

IBRI, Ivo Assad. Kósmos Noetós: a arquitetura metafísica de Charles S. Peirce. São Paulo: Paulus, 2015.

O significado de primeiridade em Schelling, Schopenhauer e Peirce. Cognitio: revista de filosofia, São Paulo, v. 9, n. 2, p. 223-234, jul./dez. 2008.

JACKSON, Bernard S. Legal semiotics and the sociology of law. Oñati: The Oñati International Institute for the Sociology of Law, 1994.

Making sense in law: linguistic, psychological and semiotic perspectives. Liverpool: Deborah Charles Publications, 1995.

JAKOBSON, Roman. Linguística e comunicação. Tradução de Izidoro Blikstein. 22. ed. São Paulo: Cultrix, 2010.

JASMIN, Marcelo Gantus; FERES JÚNIOR, João (Orgs.). História dos conceitos: debates e perspectivas. Rio de Janeiro: PUC-RJ; São Paulo: Loyola, 2006.

JOAQUÍN, Dualde. Una revolución en la lógica del derecho. Barcelona: Bosch, 1933.

KEVELSON, Roberta. Peirce, paradox, praxis: the image, the conflict, and the law. Berlin; New York: Mouton de Gruyter, 1990.

KOSELLECK, Reinhart. Uma história dos conceitos: problemas teóricos e práticos. Revista Estudos Históricos, Rio de Janeiro, v. 5, n. 10, p. 134-146, jul. 1992. ISSN 21781494. Disponível em: <http://bibliotecadigital.fgv.br/ojs/index.php/reh/article/view/1945>. Acesso em: 03 jul. 2018.

LARENZ, Karl. Methodenlehre der Rechtswissenschaft. 3. Ausg. Berlin: SpringerVerlag, 1975.

LORENZETTI, Ricardo Luís. Teoria da decisão judicial: fundamentos de direito. 2. ed. São Paulo: Revista dos Tribunais, 2010.

LYOTARD, Jean-François. A condição pós-moderna. Tradução Ricardo Corrêa Barbosa. 9. ed. Rio de Janeiro: José Olympio, 2006.

MAGARIÑOS DE MORENTIN, Juan A. El signo. Las fuentes teóricas de la semiologia: Saussure, Peirce, Morris. Buenos Aires: Hachette, 1983. 
MEDINA, José Miguel Garcia. Os poderes do juiz e o controle das decisões judiciais: estudos em homenagem a professora Teresa Arruda Alvim Wambier. São Paulo: Revista dos Tribunais, 2008.

MEIRELLES, Hely Lopes. Direito administrativo brasileiro. 33 ed. São Paulo: Malheiros, 2007.

MENDONÇA, Paulo Roberto Soares. A argumentação nas decisões judiciais. Rio de Janeiro: Renovar, 1997.

MERRELL, Floyd. Peices`s Semiotics Now. A primer. Toronto: Canadian Scholar`s Press, 1995.

MORRIS, Charles W. Fundamentos da Teoria dos Signos. Tradução de Milton José Pinto. Rio de Janeiro: Eldorado; São Paulo: EDUSP, 1976.

MÜLLER, Friedrich. Direito, linguagem, violência: elementos de uma teoria constitucional, I. Tradução de Peter Naumann. Porto Alegre: Sergio Antonio Fabris, 1995.

NALINI, José Renato. A formação da vontade judicial: fatores legais, sociais e psicológicos. Revista do Supremo Tribunal Federal, Lex, p. 6-10, mar. 1997.

O juiz, o mundo exterior e a produção da justiça. Revista dos Tribunais, São Paulo, v. 83, n. 705, p. 272-282, jul. 1994.

. O magistrado e a comunidade. Revista dos Tribunais, São Paulo, v. 80, n. 67, p. 225-231, maio. 1991.

NEVES, Antonio Castanheira. Metodologia jurídica. Coimbra: Coimbra Ed., 1993.

NÖTH, Winfried. Handbook of semiotics. Bloomington University Press, 1990.

Panorama da semiótica: de Platão a Peirce. 2. ed. São Paulo: Annablume, 1998.

A semiótica no século XX. 2. ed. São Paulo: Annablume, 1999.

OLIVEIRA, Manfredo Araújo de. Reviravolta linguístico-pragmática na Filosofia Contemporânea. 3. ed. São Paulo: Loyola, 2006.

PÊCHEUX, Michel. O Discurso: estrutura ou acontecimento. Tradução: Eni Puecinelli Orlandi. 6. ed. Campinas: Pontes, 2012.

Semântica e discurso: uma crítica à formação do óbvio. Tradução: Eni Puecinelli Orlandi. 4. ed. Campinas: UNICAMP, 2009. 
PEIRCE, Charles Sanders. Collected papers. Cambridge: Harvard University Press, 1931-1958. v. 2.

- Escritos coligidos. Seleção e Trad. Armando Mora D’Oliveira e Sérgio Pomerangblum. São Paulo: Abril Cultural, 1974.

Semiótica. 4. ed. São Paulo: Perspectiva, 2010.

Cultrix, 1972.

Semiótica e filosofia. Introd., sel. e trad. O. S. da Mota, L. Hegenberg. São Paulo:

PIGNATARI, Décio. Contracomunicação. 3. ed. Cotia: Ateliê Editorial, 2004.

. Semiótica e literatura. Cotia: Ateliê Editorial, 2004.

PRADO, Lídia Reis de Almeida. O juiz e a emoção: aspectos da lógica da decisão judicial. 6. ed. São Paulo: LTr, 2013.

REALE, Miguel. O direito como experiência. 2. ed. São Paulo: Saraiva, 2010.

A ética do juiz na cultura contemporânea. Revista Forense, Rio de Janeiro: Forense, v. 90, n. 325, p. 63-69, jan./mar. 1994.

Introdução à filosofia. 4. ed. São Paulo: Saraiva, 2007.

Lições preliminares do direito. 27. ed. São Paulo: Saraiva, 2005.

RECASÉNS SICHES, Luis. Nueva filosofia de la interpretación del derecho. México: Porrùa, 1973.

ROCHA, Leonel Severo. Epistemologia jurídica e democracia. São Leopoldo: Unisinos, 1998.

. Teoria do direito no século XXI: da semiótica à autopoiese. Seqüência: estudos jurídicos e políticos, Florianópolis, p. 193-222, jul. 2011. ISSN 2177-7055. Disponível em: $<$ https://periodicos.ufsc.br/index.php/sequencia/article/view/2177-

7055.2011v32n62p193>. Acesso em: 03 jul. 2018.

SANTAELLA, Lúcia. O método anticartesiano de C. S. Peirce. São Paulo: Ed. UNESP, 2004

O que é semiótica? São Paulo: Brasiliense, 2012.

. Semiótica aplicada. São Paulo: Cengage Learning, 2016.

Teoria geral dos signos: semiose e autogeração. São Paulo: Ática, 1995. 
SANTAELLA, Lúcia; NÖTH, Winfried. Semiótica. São Paulo: Experimento, 1999.

SAUSSURE, Ferdinand de. Curso de linguística geral. 23. ed. São Paulo: Cultrix, 2001.

SILVEIRA, Lauro Frederico Barbosa da. A comunicação de um ponto de vista pragmaticista. Cognitio: revista de filosofia, n. 2, p. 203-212, 2001.

Curso de semiótica geral. São Paulo: Quartier Latin, 2007.

STRECK, Lenio Luiz. Hermenêutica jurídica e(m) crise: uma exploração hermenêutica da construção do direito. 6. ed. Porto alegre: Livr. do Advogado, 2005.

. Hermenêutica e jurisdição: diálogos com Lenio Streck. Porto Alegre: Livr. do Advogado, 2017.

O que é isto - decido conforme minha consciência? 2. ed. Porto Alegre: Livr. do Advogado, 2010.

TARUFFO, Michele. La motivazione della sentenza civile. Padova: CEDAM, 1975.

TEIXEIRA, Sálvio de Figueiredo. A criação e realização do direito na decisão judicial. Rio de Janeiro: Forense, 2003.

TROPER, Michel. A filosofia do direito. Tradução Ana Deiró. São Paulo: Martins Fontes, 2008.

TURIN, Roti Nielba. Aulas: introdução ao estudo das linguagens. São Paulo: Annablume, 2007.

VILANOVA, Lourival. As estruturas lógicas e o sistema do direito positivo. 4. ed. São Paulo: Noeses, 2010.

WARAT, Luis Alberto. O direito e sua linguagem. 2. ed. Porto Alegre: Sergio Antonio Fabris, 1995.

. Introdução geral ao direito: a epistemologia jurídica da modernidade. Porto Alegre: Sergio Antonio Fabris, 1995.

WITTGENSTEIN, Ludwig. Tratado lógico-filosófico: investigações filosóficas. Trad. e pref. M. S. Lourenço. 3. ed. Lisboa: Fundação Calouste Gulbenkian, 2002.

ZAGREBELSKY, Gustavo. El derecho dúctil: ley, derechos, justicia. Traductor: Marina Gascon. 10. ed. Madrid: Trotta, 2011. 
ANEXO 


\section{PODER JUDICIÁRIO}

TRIBUNAL DE JUSTIÇA DO ESTADO DE SÃO PAULO

Registro: 2018.0000202789

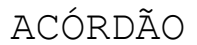

Vistos, relatados e discutidos estes autos de Agravo de Instrumento $\mathrm{n}^{\circ}$ 2052114-52.2018.8.26.0000, da Comarca de São Paulo, em que é agravante é agravada _ S. .

ACORDAM, em sessão permanente e virtual da $7^{a}$ Câmara de Direito Privado do Tribunal de Justiça de São Paulo, proferir a seguinte decisão: Deram provimento ao recurso. V. U., de conformidade com o voto do relator, que integra este acórdão.

O julgamento teve a participação dos Desembargadores MARY GRÜN (Presidente sem voto), LUIZ ANTONIO COSTA E MIGUEL BRANDI .

São Paulo, 23 de março de 2018 .

\section{José Rubens Queiroz Gomes Relator}

Assinatura Eletrônica 
VOTO $\mathrm{N}^{\circ} 10559$

AGRAVO DE INSTRUMENTO $\mathrm{N}^{\circ}$ 2052114-52.2018.8.26.0000

COMARCA: SÃO PAULO - $3^{a}$ VARA DA FAMÍLIA E SUCESSÕES

JUIZ (A) DE $1^{\text {a }}$ INSTÂNCIA: RICARDO CUNHA DE PAULA

AGRAVANTE :

AGRAVADO :

$7^{\circ}$ CÂMARA DE DIREITO PRIVADO

AGRAVO DE INSTRUMENTO. Decisão que extinguiu a ação, parcialmente, em relação ao pedido de "posse compartilhada e regime de visitas" de cão de estimação do casal, por entender o MM. Juiz singular que 0 Juízo da Família e Sucessões não é competente, pois a questão é cível. Competência para julgar - pedido que é do juízo da $3^{a}$ Vara de Família e Sucessões do Foro Central, em que se discute $o$ reconhecimento e dissolução de união estável. Recurso a que se dá provimento.

Trata-se de agravo de instrumento contra

a r. decisão que extinguiu a ação, parcialmente, em relação ao pedido de "posse compartilhada e regime de visitas" de cão de estimação do casal, por entender o MM. Juiz singular que o Juízo da Família e Sucessões não é competente, pois a questão é cível.

Alega o agravante que se trata de questão decorrente do termino da união estável, que deve ser resolvida pelo Juízo de Família, e não pelo Juízo Cível.

Deixa-se de intimar a agravada, pois esta ainda não participa do feito.

É a síntese do necessário.

O recuso comporta provimento. 


\section{PODER JUDICIÁRIO \\ TRIBUNAL DE JUSTIÇA DO ESTADO DE SÃO PAULO}

Sobre o tema, já foi decidido por este

Tribunal:

"No Código Civil de 2002, os animais são tratados como objetos destinados a circular riquezas (art. 445, \$ 20), garantir dívidas (art. 1.444) ou estabelecer responsabilidade civil (art. 936).

Com isso, é possivel afirmar que a relação afetiva existente entre seres humanos e animais não foi regulada pelo referido diploma. A propósito, tamanha é a notoriedade do referido vínculo atualmente que, com base em pesquisa recente do IBGE, é possível afirmar que há mais cães de estimação do que crianças em lares brasileiros (http://oglobo.globo.com/sociedade/saude/brasil-tem-mais-cachorrosde-estimacao-do-que-criancas-diz-pesquisa-doibge-16325739).

Diante disso, pode-se dizer que há uma lacuna legislativa, pois a lei não prevê como resolver conflitos entre pessoas em relação a um animal adquirido com a função de proporcionar afeto, não riqueza patrimonial.

Nesses casos, deve o juiz decidir "de acordo com a analogia, os costumes e os princípios gerais de direito", nos termos do art. $4^{\circ}$ da Lei de Introdução às Normas de Direito Brasileiro.

Considerando que na disputa por um animal de estimação entre duas pessoas após o término de um casamento e de uma união estável há uma semelhança com o conflito de guarda e visitas de uma criança ou de um adolescente, mostra-se possível a aplicação analógica dos 


\section{PODER JUDICIÁRIO \\ TRIBUNAL DE JUSTIÇA DO ESTADO DE SÃO PAULO}

arts. 1.583 a 1.590 do Código Civil, ressaltando-se que a guarda e as visitas devem ser estabelecidas no interesse das partes, não do animal, pois o afeto tutelado é o das pessoas.

Todavia, isso não significa que a saúde do bicho de estimação não é levada em consideração, visto que o art. 32 da Lei no 9.605/1998 pune com pena privativa de liberdade e multa quem "praticar ato de abuso, maus-tratos, ferir ou mutilar animais (...) domésticos ou domesticados".

Por conseguinte, de se aplicar a analogia acima referida, estando a ação de reconhecimento e dissolução de união estável em trâmite na $3^{a}$ Vara de Família e Sucessões do Foro Central, é deste juízo a competência para o julgamento da ação em que se discute a "posse compartilhada e visitação" do animal doméstico.

Nesse sentido:

"CONFLito NEGATiVo dE COMPETÊNCIA. Ação de guarda de animal doméstico adquirido na constância de relacionamento amoroso. Competência para julgar a demanda do juízo em que se discute o reconhecimento e dissolução de união estável. Conflito julgado procedente. Competência do Juízo da $3^{a}$ Vara da Família e Sucessões do Foro Regional do Jabaquara da Comarca da Capital, ora suscitado." (Conflito de competência $n^{\circ}$ 0026423-07.2017.8.26.0000, relator Issa Ahmed, j. 04/12/2017)

Posto isto, dá-se provimento ao recurso.

\section{JOSÉ RUBENS QUEIROZ GOMES \\ Relator}

